\title{
Systematic review of deep learning and machine learning models in biofuels research
}

\author{
Sina Ardabilii ${ }^{1}$, Amir Mosavi ${ }^{2,3^{*}}$ and Annamaria R. Varkonyi-Koczy ${ }^{2,4}$ \\ ${ }^{1}$ Institute of Advanced Studies Koszeg, Koszeg, Hungary \\ ${ }^{2}$ Kalman Kando Faculty of Electrical Engineering, Obuda University, Budapest, Hungary \\ ${ }^{3}$ School of the Built Environment, Oxford Brookes University, Oxford OX3 OBP, UK \\ ${ }^{4}$ Department of Mathematics and Informatics, J. Selye University, Komarno, Slovakia \\ *a.mosavi@broookes.ac.uk
}

\begin{abstract}
Biofuels construct an essential pillar of energy systems. Biofuels are considered as a popular resource for electricity production, heating, household, and industrial usage, liquid fuels, and mobility around the world. Thus, the need for handling, modeling, decision-making, demand, and forecasting for biofuels are of utmost importance. Recently, machine learning (ML) and deep learning (DL) techniques have been accessible in modeling, optimizing, and handling biofuels production, consumption, and environmental impacts. The main aim of this study is to review and evaluate ML and DL techniques and their applications in handling biofuels production, consumption, and environmental impacts, both for modeling and optimization purposes. Hybrid and ensemble ML methods, as well as DL methods, have found to provide higher performance and accuracy in modeling the biofuels.
\end{abstract}

Keywords: Biofuels, deep learning, big data, machine learning models, biodiesel 


\section{Nomenclatures}

\begin{tabular}{|c|c|c|c|}
\hline Artificial neural network & ANN & Random forest & $\mathrm{RF}$ \\
\hline Extreme learning machine & ELM & Non-random two-liquid & NRTL \\
\hline Machine learning & ML & Recurrent neural network & RNN \\
\hline Support vector machine & SVM & Partial least squares & PLS \\
\hline Wavelet neural networks & WNN & Discriminant analysis & DA \\
\hline Deep learning & DL & Principal component analysis & PCA \\
\hline $\begin{array}{l}\text { Autoregressive integrated } \\
\text { moving average }\end{array}$ & ARIMA & Linear discriminant analysis & LDA \\
\hline Feed-forward neural networks & FFNN & Support vector regression & SVR \\
\hline Multi layered perceptron & MLP & Least-squares & $\mathrm{LS}$ \\
\hline Decision tree & DT & Sparse Bayesian & SB \\
\hline $\begin{array}{l}\text { Response surface methodol- } \\
\text { ogy }\end{array}$ & RSM & Multi criteria decision making & MCDM \\
\hline $\begin{array}{l}\text { Back propagation neural net- } \\
\text { work }\end{array}$ & BPNN & Genetic programming & GP \\
\hline Centroid mean & $\mathrm{CM}$ & Multi linear regression & MLR \\
\hline $\begin{array}{l}\text { Adaptive neuro fuzzy infer- } \\
\text { ence system }\end{array}$ & ANFIS & $\begin{array}{l}\text { Step-wise Weight } \text { Assess- } \\
\text { ment Ratio Analysis }\end{array}$ & SWARA \\
\hline Analytic network process & ANP & $\begin{array}{l}\text { Multi Objective Optimization } \\
\text { by Ratio Analysis }\end{array}$ & MOORA \\
\hline
\end{tabular}




\section{Introduction}

The global energy systems are highly dependent on fossil fuels [1, 2]. The importance of energy systems and their role in economics and politics is not hidden for anyone [3, 4]. This issue is not only important for the advanced industrialized countries, which are major energy consumers but is also essential for oil-rich countries [5]. Because countries have to understand the fact that fossil fuel resources are limited resources. In addition to the nature of these fuels, which contains polluting substances, the issue of their ending up has aggravated the growing concern. Therefore owing to depleting non-renewable energy resources, pollution, and environmental damage, the world is turning towards renewable energy resources [6]. Fossil fuels remain as one of the major energy resources worldwide [7]. Heavy dependence on fossil fuels has caused an energy crisis. Using fossil fuel for economic activities leads to GHG emissions from almost all regions of the world [8]. Renewable resources like biofuels make an attractive contribution towards meeting the growing demand for energy supply [9-11]. Owing to environmental concerns and the rise and fluctuations in the fossil fuel resources, worldwide interests have moved towards biodiesel, a clean and renewable alternative for fossil fuels $[12,13]$. Biofuels can be used in different fields for energy production like electricity production, power production, or transportation [14]. The economy of biofuels and related refineries will be shaped by policies that have shaped the economy of hydrocarbon and its refineries over the last century [15-18]. Due to the environmental benefits of biofuels, their contribution to the automotive fuel market is increasing sharply. Various scenarios have been written about the estimated biofuels from different sources in the future energy system. The availability of biofuels for the electricity market, heating, and liquid fuels is very important. Therefore the need for handling, modeling, decision making, and forecasting for biofuels can be one of the main challenges for scientists [19-22]. Figure.1 shows the research trend in literature considering biofuels. Note that, since 2015 the research in this realm has stopped been progressing. 


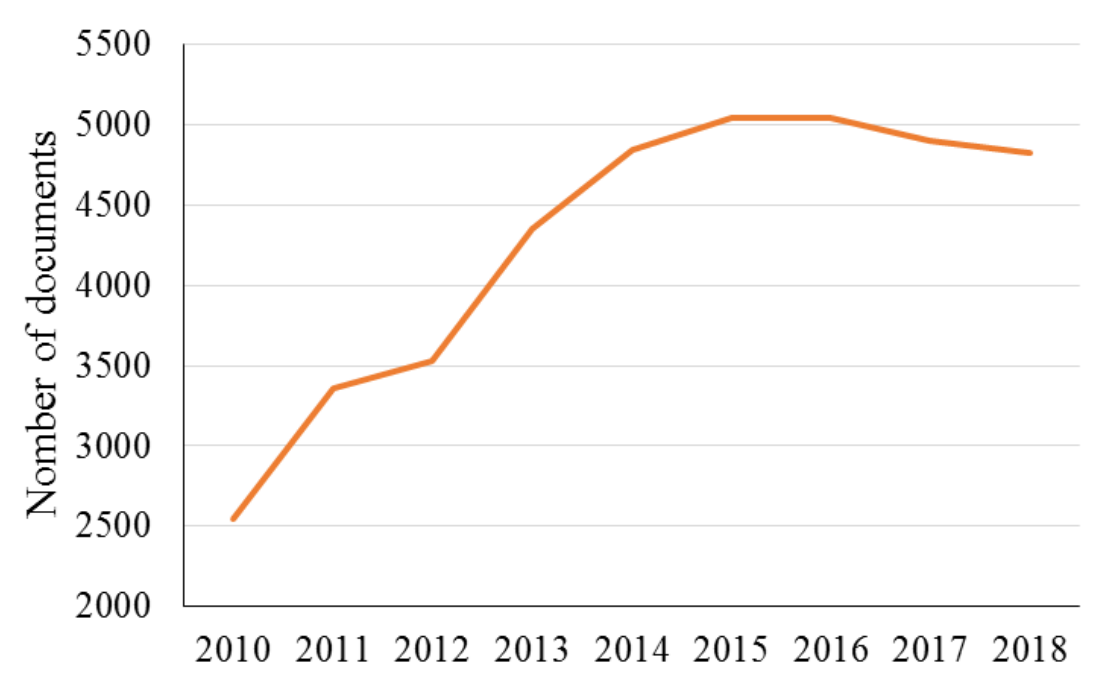

Fig. 1. The research trend in literature considering biofuels research (source: web of science )

Recently, machine learning and deep learning techniques have been accessible in modeling, optimizing and handling the biodiesel production, consumption, and its environmental impacts by considering the effect of parameters on biofuel production yield because the production of the desired product needs an effective use of experimental model [23]. These methods provide an independent modeling approach to the nature of the process or its mathematical models and are able to model the process with high accuracy $[9,11,24,25]$.

The primary purpose of this study is to present a review in a specific field to find the strengths and weaknesses of the field and to provide a complete background. The main aim of this study is to evaluate the ML and DL techniques developed for handling biofuels production, consumption, and environmental impacts, both for modeling and optimization purposes. The study initially explains and defines different biofuels. Then provides a general survey about the characteristics and the basis of the developed studies. In the next stage, explains the state of art of the DL and ML techniques employed in the field. Finally, concludes the results and achievements and proposes the strengths and weakness of different DL and ML techniques. 


\section{ML and DL methods in biofuels research}

The application of ML and DL methods in various scientific and engineering domains have been previously investigated [26-40]. Generally, the ML methods are reported to be further advancing to through ensemble and hybrid techniques [40-78 ]. On the other hand, the DL methods are still considered as a new phenomenon and are slowly progressing.

In this section, the most popular ML and DL methods in biofuels research are identified and reviewed. During the past decade, the application of these intelligent algorithms has been dramatically increases in biofuels research. Figure 2. represents the increasing demand and popularity of using DL and ML in handling biofuels. It is apparent that since 2010, the use of DL and ML has been increasing until the year 2017. Since then, it starts to decline. The reason can be found in the overall decrease in the number of literature in biofuels research. We made three classifications of the methods, i.e., neural networks-based methods, single ML methods, and a separate group for deep learning, ensembles, and hybrid models.

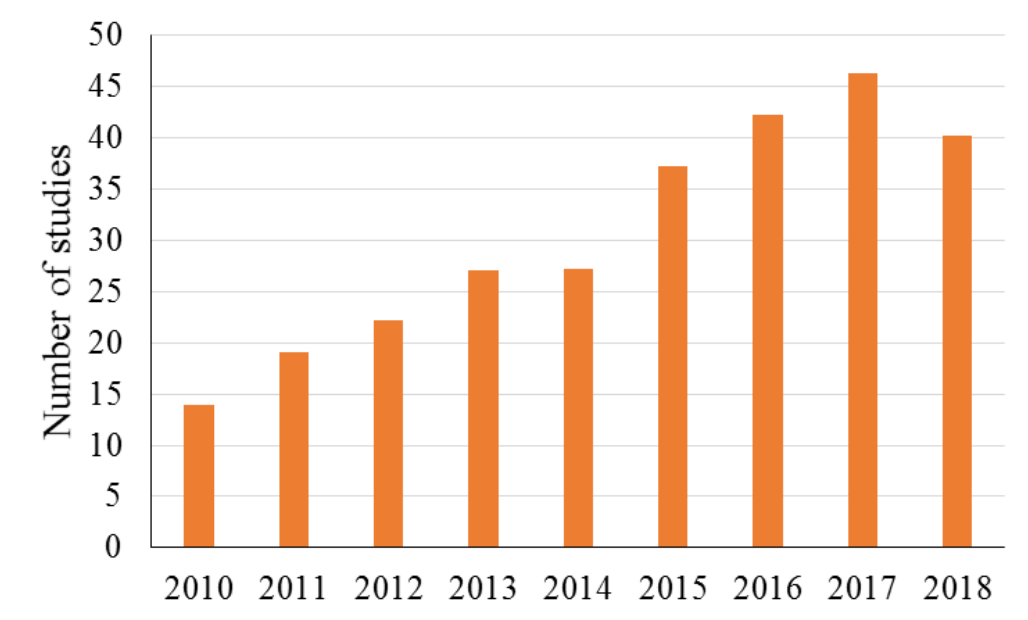

Fig. 2. Demand and popularity of using DL and ML in biofuels research (source: web of science) 


\subsection{Neural networks-based ML models for biofuels research}

This section includes the application of artificial neural networks (ANNs), Multilayer perceptron (MLP), Extreme learning machines (ELM), feedforward neural networks (FFNNs) and Backpropagation ANNs in biofuels research.

Table 1. top studies developed by ANN-based methods in biofuel

\begin{tabular}{|c|c|c|c|}
\hline 苞 & Contribution & method & Application domains \\
\hline [59] & $\begin{array}{l}\text { To optimize the prediction of liquid-liquid equilibria } \\
\text { which is employed in the simulation of the biofuel } \\
\text { process by the use of a novel non-random two-liquid- } \\
\text { ANN method. }\end{array}$ & $\begin{array}{l}\text { NRTL- } \\
\text { ANN }\end{array}$ & $\begin{array}{l}\text {-NRTL } \\
\text {-Biofuels }\end{array}$ \\
\hline [9] & $\begin{array}{l}\text { To develop different types of MLP networks for the } \\
\text { estimation of enzyme function. }\end{array}$ & MLP & $\begin{array}{l}\text {-Enzyme function } \\
\text {-machine learning }\end{array}$ \\
\hline$[60]$ & $\begin{array}{l}\text { To develop the ANN method for the prediction of un- } \\
\text { measurable variables during hydrogen and methane } \\
\text { production through the anaerobic digestion process. }\end{array}$ & RNN & $\begin{array}{l}\text {-Biofuels } \\
\text {-RNN }\end{array}$ \\
\hline$[61]$ & $\begin{array}{l}\text { To develop a comprehensive survey about the use of } \\
\text { ANN in the optimization and estimation of variables } \\
\text { in the biofuels production process }\end{array}$ & ANN & $\begin{array}{l}\text {-ANN } \\
\text {-Biofuel production }\end{array}$ \\
\hline$[25]$ & $\begin{array}{l}\text { To employ ANN methods for the prediction of the } \\
\text { cetane number of biofuel samples in the presence of } \\
\text { furanic additives }\end{array}$ & ANN & $\begin{array}{l}\text {-Machine learning } \\
\text {-Biofuels }\end{array}$ \\
\hline
\end{tabular}


Reynel-Ávila et al. [59] developed an innovative hybrid non-random two-liquidANN method in order to increase the estimation performance of the liquid-liquid equilibria, which is used to simulate the biofuel process. Non-random two-liquid method is considered as a thermodynamic method to be used in a multi-component system. Therefore, hybridization of this method with the ANN method can improve the system accuracy for the regression and fitting proposes. Evaluation of the proposed method has been performed using RMSD factor for measuring the agreement between target and estimated values. This method as a flexible method, could successfully cope with the estimation task as well as increasing the accuracy of estimation.

Concu et al. [9] developed a study in order to employ different machine learning techniques for the estimation of protein function through a conversion process as a type of enzyme for considering in bioethanol production. The developed machine learning techniques included the single method containing different architectures of MLP methodology. Results have been evaluated using accuracy, sensitivity, and specificity. Methods have a different number of neurons in the hidden layer. The accuracy of the proposed MLP method was acceptable, as well as its higher sustainability. Camberos et al. [60] developed a recurrent neural network method in order to estimate un-measurable variables during hydrogen and methane production through the anaerobic digestion process. The reason was the ability of the recurrent ANNs method in predicting the behavior of unknown and sophisticated systems. The method was a single method which benefited the external disturbances as well as the parameter uncertainties. The results have been evaluated using mean square error. Based on results, the proposed RNN method could successfully provide a high performance in confrontation with the complex system. Also, the method provided a high sustainability by a high stability in the presence of the external distributions.

Sewsynker-Sukai [61] did a comprehensive survey about the application of ANN, as one of the most popular and applied machine learning methods, in the field of biofuels for optimization and estimation purposes. This study also presents a brief explanation 
of the comparison of the performance of ANN with another method and discussing the architectures of the developed ANN methods. Comparisons were performed using the coefficient of determination as to the performance factor. Based on results, developing ANN methods in this field provides a high production performance as well as reducing the time and the cost consuming. Reduction of the time and cost in the biofuels production and consuming processes also increases the sustainability and reliability of the system. Therefore, ANN can be a useful tool for handling biofuels and for managing the production and consuming processes for policymakers in the future researches. Kessler et al. [25] presented a study to estimate the cetane number of biofuel samples in the presence of furanic additives. Results have been evaluated using RMSE values. ANN as a predictive method could be successfully applied for the prediction of cetane number with a low error.

Different applications of ANN tools in different fields of biofuels have been already discussed. However, there is a need for metrics and different criteria for the evaluation of the performance of each method. Table 2 present a brief comparison of the accuracy, reliability, and sustainability of methods developed for handling biofuels using different types of ANN methods. These factors have been prepared and presented based on different aspects which have been concluded by the reviewed studies.

Table 2. the comparison results of ANN-based methods for biofuels handling

\begin{tabular}{|l|l|l|l|l|l|}
\hline Method & Application & Accuracy & Reliability & Sustainability & Reference \\
\hline Hybrid NRTL-ANN & Estimation & ++ & ++ & ++ & {$[59]$} \\
\hline MLP & Estimation & ++ & + & + & {$[9]$} \\
\hline RNN & Estimation & +++ & +++ & +++ & {$[60]$} \\
\hline
\end{tabular}




\begin{tabular}{|l|l|l|l|l|l|}
\hline ANN & Estimation & ++ & + & + & {$[61]$} \\
\hline ANN & Optimization & ++ & ++ & + & {$[61]$} \\
\hline ANN & estimation & ++ & + & + & {$[25]$} \\
\hline
\end{tabular}

\subsection{Further single ML methods for biofuels research}

This section includes support vector machines (SVM), decision trees (DTs) regression tree (RTs), Bayesian, k-means, and k-nearest neighbors, presented in table 3.

Table 3. top studies developed by SVM based methods in biofuel

\begin{tabular}{|c|c|c|c|}
\hline : & Contribution & Method & Application domains \\
\hline$[62]$ & $\begin{array}{l}\text { To develop PLS-DA, SVM and PCA- } \\
\text { LDA methods for the classification of } \\
\text { biofuels }\end{array}$ & $\begin{array}{l}\text { PLS-DA, SVM, and } \\
\text { PCA-LDA }\end{array}$ & $\begin{array}{l}\text {-Classification } \\
\text {-SVM }\end{array}$ \\
\hline [63] & $\begin{array}{l}\text { To develop prediction models for the es- } \\
\text { timation of biofuels pellet quality using } \\
\text { LSSVM and PLSR methods as non-de- } \\
\text { structive methods }\end{array}$ & LSSVM and PLSR & $\begin{array}{l}\text {-LSSVM } \\
\text {-PLSR }\end{array}$ \\
\hline
\end{tabular}




\begin{tabular}{|c|l|l|l|}
\cline { 3 - 4 }$[64]$ & $\begin{array}{l}\text { To develop a fuzzy method for the pre- } \\
\text { diction of a cetane number of biodiesel } \\
\text { fuel samples }\end{array}$ & Fuzzy & -Fuzzy \\
\hline$[65]$ & $\begin{array}{l}\text { To develop a hybrid modeling method } \\
\text { for the estimation of the engine perfor- } \\
\text { mance fuelled by biofuel }\end{array}$ & SBELM & -Cetane number \\
\hline$[66]$ & $\begin{array}{l}\text { To employ hybrid machine learning } \\
\text { techniques for the estimation of biofuel } \\
\text { production yield and optimization pro- } \\
\text { duction process }\end{array}$ & $\begin{array}{l}\text { ELM-RSM } \\
\text { SVM-RSM }\end{array}$ & - and \\
\hline
\end{tabular}

Mancini et al. [62] developed three methods including partial least squares discriminant analysis, SVM, and principal component analysis linear discriminant analysis for the classification of biofuels. Based on results, all the methods could successfully cop with the classification task but SVM has the best classification performance. Feng et al. [63] developed non-destructive prediction methods for the estimation of the quality of the biofuel pellet using partial least-squares regression and a least-squares support vector machine as non-destructive diagnosis methods to be compound with successive projections algorithm. The performance of the methods have been compared using the determination coefficient and root mean square error values. Based on results, the best method was identified to be SPA-LSSVM method as a hybrid diagnosis method. This method employs the advantages of both LSSVM and SPA methods, consequently.

Faizollahzadeh et al. [64] developed a Sugeno based fuzzy method for the prediction of biodiesel fuel cetane number in the presence of Carbon number, Double bond, Saponification number, and Iodine value. The performance of the developed model has been calculated using the determination coefficient, and root mean square error. The developed model has high accuracy in both training and testing steps, but one of the 
most critical factors for this method was its lower processing time and its user-friendly application. These factors increase the method of sustainability factor to be employed in future researches. Wong et al. [65] developed a novel hybrid sparse Bayesian-based extreme learning machine technique for the estimation of the engine performance fuelled by biofuel as well as the calibration of the ECU. The proposed method has been also compared with the performance of ELM, Bayesian ELM and back propagation neural network in terms of mean absolute percentage error and standard deviation. The proposed hybrid method has an acceptable accuracy in both training and testing steps compared with that for the ELM, BPNN, and BELM methods. The proposed method also has a higher performance in the estimation of engine emissions.

Faizollahzadeh et al. [66] developed an innovative hybrid ELM-RSM and EVM RSM methods for the prediction of biofuel production yield and optimization of the production process for accessing a higher production yield. The developed methods have been compared with SVM, ANN and ANFIS methods in term of performance factors for the prediction phase. Based on results, hybrid ELM-RSM methods could provide higher performance by increasing the production yield compared with that of the other methods. This study also indicates the importance and strength of the hybrid method over single methods. In fact, this method benefits the highest prediction capability of ELM method in parallel with the optimization capability of the RSM. Therefore this study highlights the highest performance of hybrid techniques in comparison with single ones. Table 4 presents the comparison results of SVM based methods for biofuels handling.

Table 4. the comparison results of SVM based methods for biofuels handling

\begin{tabular}{|l|l|c|c|c|l|}
\hline Method & Application & Accuracy & Reliability & Sustainability & Reference \\
\hline SVM & classification & ++ & ++ & ++ & {$[62]$} \\
\hline PCA-LDA & classification & ++ & + & + & {$[62]$} \\
\hline
\end{tabular}




\begin{tabular}{|l|l|l|l|l|l|}
\hline PLS-DA & classification & + & + & + & {$[62]$} \\
\hline SPA-LSSVM & classification & +++ & +++ & ++ & {$[63]$} \\
\hline Fuzzy & Estimation & +++ & +++ & ++ & {$[64]$} \\
\hline SBELM & Estimation & +++ & +++ & +++ & {$[65]$} \\
\hline ELM & Estimation & + & + & + & {$[65]$} \\
\hline BELM & Estimation & ++ & + & + & {$[65]$} \\
\hline ELM-RSM & Optimization & +++ & +++ & +++ & {$[66]$} \\
\hline SVM-RSM & Optimization & +++ & ++ & ++ & {$[66]$} \\
\hline
\end{tabular}

\subsection{Deep learning, machine learning, ensembles, and hybrid models for} biofuels research

In this section, the more sophisticated ML methods in addition to DL are presented. Here may include neuro-fuzzy models, various DL models, and ensemble MLs, presented in table 5 .

Table 5. top studies developed by machine and deep learning-based methods in biofuel

\begin{tabular}{|c|c|c|c|}
\hline 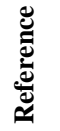 & Contribution & Method & Research domain \\
\hline
\end{tabular}




\begin{tabular}{|l|l|l|l|}
\cline { 3 - 4 }$[67]$ & $\begin{array}{l}\text { To develop a novel Multi-criteria deci- } \\
\text { sion making for improving the energy } \\
\text { management system and increasing the } \\
\text { energy efficiency }\end{array}$ & MCDM & -Decision making \\
\hline$[68]$ & $\begin{array}{l}\text { To develop different methods including } \\
\text { hybrid and single methods for the pre- } \\
\text { diction of short term energy parameters }\end{array}$ & $\begin{array}{l}\text { ANFIS-CM, Genetic } \\
\text { programming, M5Tree, } \\
\text { RF and MLR }\end{array}$ & -Hybrid machine learning \\
\hline [22] & $\begin{array}{l}\text { To develop a comprehensive survey } \\
\text { about the application of machine learn- } \\
\text { ing and deep learning methods in energy } \\
\text { systems }\end{array}$ & $\begin{array}{l}\text { Machine learning and } \\
\text { deep learning methods }\end{array}$ & -Energy systems \\
\hline
\end{tabular}

Erdogan et al. [67] developed a novel multi-criteria decision-making system for choosing the best biodiesel fuel for a compression ignition engine in terms of engine performance and combustion characteristics. Based on results, the hybrid Step-wise Weight Assessment Ratio Analysis- Multi-Objective Optimization by Ratio Analysis method and hybrid Analytic network process- Multi-Objective Optimization by Ratio Analysis provided the best performance for choosing the best fuel sample.

Deo et al. [68] developed different hybrid and single machine learning techniques for the prediction of sub-tropical photo-synthetically active radiation. The developed methods included ANFIS integrated with centroid mean, random forest, genetic programming, M5Tree, and multiple linear regression. Methods have been compared in terms of mean absolute error and root mean square error. Results indicated that the hybrid ANFIS-CM followed by GP methods could provide the lowest error as well as the highest sustainability.

Mosavi et al. [22] developed a comprehensive survey about the application of machine learning methods, including single and hybrid methods in the energy systems. The study has been developed in order to present a comprehensive state of the art of machine learning and to discuss their advantage and disadvantages, in detail. Methods 
have been compared in terms of root mean square error, determination coefficient, correlation coefficient, and mean absolute percentage error. Based on results available in table 6 . the hybrid machine learning have the best performance for prediction and optimization, which can help policymakers for developing accurate energy management systems.

Table 6. the comparison results of DL and ML-based methods for biofuels handling

\begin{tabular}{|c|c|c|c|c|c|}
\hline Method & Application & Accuracy & Reliability & Sustainability & Reference \\
\hline $\begin{array}{l}\text { SWARA- } \\
\text { MOORA }\end{array}$ & Decision making & +++ & +++ & +++ & [67] \\
\hline ANP-MOORA & Decision making & +++ & +++ & +++ & [67] \\
\hline ANFIS-CM & classification & +++ & +++ & +++ & [68] \\
\hline GP & classification & +++ & ++ & ++ & [68] \\
\hline Hybrid ML & Estimation & +++ & +++ & +++ & {$[22]$} \\
\hline Single ML & Estimation & +++ & ++ & ++ & [22] \\
\hline Hybrid ML & Optimization & +++ & +++ & +++ & [22] \\
\hline Single ML & Optimization & +++ & +++ & ++ & {$[22]$} \\
\hline
\end{tabular}

\section{Conclusion}

This paper studies the applications and progress of ML and DL methods biofuels research. This study presents an in-depth survey and analysis of the 'hybrid model' and 
ensemble models that integrate two or more techniques. Survey shows that the single ML methods except for ANNs, have not been popular. However, the ensemble and hybrid models have emerged and continue to advance for higher accuracy and better performance. DL techniques also will bring a tremendous amount of intelligence for better prediction models. In general, modeling, forecasting, and decision making about the future of biofuels help for developing sustainable energy resources, which are lowcost resources with low environmental impacts. ML and DL techniques have been successfully employed in all fields of sciences and have improved the process. The various combinations of the hybrid and ensemble methods are found to be the most effective in handling biofuels.

\section{Acknowledgments}

This publication has been supported by the Project: "Support of research and development activities of the J. Selye University in the field of Digital Slovakia and creative industry" of the Research \& Innovation Operational Programme (ITMS code: NFP313010T504) co-funded by the European Regional Development Fund.

\section{References}

1. Landis, D.A., et al., Biomass and biofuel crop effects on biodiversity and ecosystem services in the North Central US. Biomass and Bioenergy, 2018. 114: p. 18-29.

2. Shaosen, S., et al., Experimental and artificial intelligence for determination of stable criteria in cyclic voltammetric process of medicinal herbs for biofuel cells. International Journal of Energy Research, 2019.

3. Wong, K.I. and P.K. Wong, Optimal calibration of variable biofuel blend dualinjection engines using sparse Bayesian extreme learning machine and metaheuristic optimization. Energy Conversion and Management, 2017. 148: p. 1170-1178. 
4. Wong, K.I. and P.K. Wong, Adaptive air-fuel ratio control of dual-injection engines under biofuel blends using extreme learning machine. Energy Conversion and Management, 2018. 165: p. 66-75.

5. Zhang, F., et al., Integrating GIS with optimization method for a biofuel feedstock supply chain. Biomass and Bioenergy, 2017. 98: p. 194-205.

6. Afsharzade, N., et al., Renewable energy development in rural areas of Iran. Renewable and Sustainable Energy Reviews, 2016. 65: p. 743-755.

7. Fardad, K., Producing Biogas from Medicinal Plants, in Biosystem Engineering. 2017, University of Mohaghegh Ardabili: Ardabil, Iran.

8. Ben Jebli, M. and S. Ben Youssef, The role of renewable energy and agriculture in reducing CO2 emissions: evidence for North Africa countries. 2015.

9. Concu, R., et al., PTML Model of Enzyme Subclasses for Mining the Proteome of Biofuel Producing Microorganisms. Journal of Proteome Research, 2019.

10. De Bortoli, A.L. and F.N. Pereira, Obtaining a reduced kinetic mechanism for Methyl Butanoate. Journal of Mathematical Chemistry, 2019. 57(3): p. 812-833.

11. del Rio-Chanona, E.A., et al., Deep learning-based surrogate modeling and optimization for microalgal biofuel production and photobioreactor design. AIChE Journal, 2019. 65(3): p. 915-923.

12. Demirbas, A., Global biofuel strategies. Energy Education Science and Technology, 2006. 17(1/2): p. 27.

13. Xue, J., T.E. Grift, and A.C. Hansen, Effect of biodiesel on engine performances and emissions. Renewable and sustainable energy reviews, 2011. 15(2): p. 1098-1116.

14. Seyyed aram, A. and B. Najafi, The effect of biodiesel of butanol alcohol and waste oil on performance and emission of diesel engine, in Biosystem engineering. 2016, Thesis of MSc, University of Mohaghegh Ardabili. 
15. Nicoletti, J., C. Ning, and F. You, Incorporating agricultural waste-to-energy pathways into biomass product and process network through data-driven nonlinear adaptive robust optimization. Energy, 2019. 180: p. 556-571.

16. Opgenorth, P., et al., Lessons from Two Design-Build-Test-Learn Cycles of Dodecanol Production in Escherichia coli Aided by Machine Learning. ACS Synthetic Biology, 2019. 8(6): p. 1337-1351.

17. Rezk, H., et al., Improving the environmental impact of palm kernel shell through maximizing its production of hydrogen and syngas using advanced artificial intelligence. Science of the Total Environment, 2019. 658: p. 1150-1160.

18. Salmeron, J.L. and A. Ruiz-Celma, Elliot and symmetric elliot extreme learning machines for Gaussian noisy industrial thermal modelling. Energies, 2019. 12(1).

19. Ghaderi, M., et al., An analysis of noise pollution emitted by moving MF285 Tractor using different mixtures of biodiesel, bioethanol and diesel through artificial intelligence. Journal of Low Frequency Noise Vibration and Active Control, 2019. 38(2): p. 270-281.

20. Habyarimana, E., et al., Towards predictive modeling of sorghum biomass yields using fraction of absorbed photosynthetically active radiation derived from sentinel-2 satellite imagery and supervised machine learning techniques. Agronomy, 2019. 9(4).

21. Kumar, S., et al., Thermozymes: Adaptive strategies and tools for their biotechnological applications. Bioresource Technology, 2019. 278: p. 372-382.

22. Mosavi, A., et al., State of the art of machine learning models in energy systems, a systematic review. Energies, 2019. 12(7).

23. Muthukumaran, C., et al., Process optimization and kinetic modeling of biodiesel production using non-edible Madhuca indica oil. Fuel, 2017. 195: p. 217-225.

24. Anderson, R., et al., An integrated modeling framework for crop and biofuel systems using the DSSAT and GREET models. Environmental Modelling and Software, 2018. 108: p. $40-50$. 
25. Kessler, T., et al., Artificial neural network based predictions of cetane number for furanic biofuel additives. Fuel, 2017. 206: p. 171-179.

26. Choubin, B., et al., An ensemble prediction of flood susceptibility using multivariate discriminant analysis, classification and regression trees, and support vector machines. Science of the Total Environment, 2019. 651: p. 2087-2096.

27. Dehghani, M., et al., Prediction of hydropower generation using Grey wolf optimization adaptive neuro-fuzzy inference system. Energies, 2019. 12(2).

28. Dineva, A., et al., Review of soft computing models in design and control of rotating electrical machines. Energies, 2019. 12(6).

29. Dineva, A., et al., Multi-Label Classification for Fault Diagnosis of Rotating Electrical Machines. 2019.

30. Farzaneh-Gord, M., et al., Numerical simulation of pressure pulsation effects of a snubber in a CNG station for increasing measurement accuracy. Engineering Applications of Computational Fluid Mechanics, 2019. 13(1): p. 642-663.

31. Ghalandari, M., et al., Investigation of submerged structures' flexibility on sloshing frequency using a boundary element method and finite element analysis. Engineering Applications of Computational Fluid Mechanics, 2019. 13(1): p. 519-528.

32. Ghalandari, M., et al., Flutter speed estimation using presented differential quadrature method formulation. Engineering Applications of Computational Fluid Mechanics, 2019. 13(1): p. 804-810.

33. Karballaeezadeh, N., et al., Prediction of remaining service life of pavement using an optimized support vector machine (case study of Semnan-Firuzkuh road). Engineering Applications of Computational Fluid Mechanics, 2019. 13(1): p. 188-198.

34. Menad, N.A., et al., Modeling temperature dependency of oil - water relative permeability in thermal enhanced oil recovery processes using group method of data handling and gene expression programming. Engineering Applications of Computational Fluid Mechanics, 2019. 13(1): p. 724-743. 
35. Mohammadzadeh, S., et al., Prediction of Compression Index of Fine-Grained Soils Using a Gene Expression Programming Model. Infrastructures, 2019. 4(2): p. 26.

36. Mosavi, A. and M. Edalatifar, A Hybrid Neuro-Fuzzy Algorithm for Prediction of Reference Evapotranspiration, in Lecture Notes in Networks and Systems. 2019, Springer. p. 235-243.

37. Mosavi, A., A. Lopez, and A.R. Varkonyi-Koczy, Industrial applications of big data: State of the art survey, D. Luca, L. Sirghi, and C. Costin, Editors. 2018, Springer Verlag. p. 225-232.

38. Mosavi, A., P. Ozturk, and K.W. Chau, Flood prediction using machine learning models: Literature review. Water (Switzerland), 2018. 10(11).

39. Mosavi, A. and T. Rabczuk, Learning and intelligent optimization for material design innovation, D.E. Kvasov, et al., Editors. 2017, Springer Verlag. p. 358-363.

40. Mosavi, A., T. Rabczuk, and A.R. Varkonyi-Koczy, Reviewing the novel machine learning tools for materials design, D. Luca, L. Sirghi, and C. Costin, Editors. 2018, Springer Verlag. p. 50-58.

41. Aram, F., et al., Design and validation of a computational program for analysing mental maps: Aram mental map analyzer. Sustainability (Switzerland), 2019. 11(14).

42. Asadi, E., et al., Groundwater Quality Assessment for Drinking and Agricultural Purposes in Tabriz Aquifer, Iran. 2019.

43. Asghar, M.Z.; Subhan, F.; Imran, M.; Kundi, F.M.; Shamshirband, S.; Mosavi, A.; Csiba, P.; R. Várkonyi-Kóczy, A. Performance Evaluation of Supervised Machine Learning Techniques for Efficient Detection of Emotions from Online Content. Preprints 2019, 2019080019 (doi: 10.20944/preprints201908.0019.v1).

44. Bemani, A.; Baghban, A.; Shamshirband, S.; Mosavi, A.; Csiba, P.; Várkonyi-Kóczy, A.R. Applying ANN, ANFIS, and LSSVM Models for Estimation of Acid Sol-vent Solubility in Supercritical CO2. Preprints 2019, 2019060055 (doi: 10.20944/preprints201906.0055.v2). 
45. Choubin, B., et al., Snow avalanche hazard prediction using machine learning methods. Journal of Hydrology, 2019. 577.

46. Mosavi, A., et al., Prediction of multi-inputs bubble column reactor using a novel hybrid model of computational fluid dynamics and machine learning. Engineering Applications of Computational Fluid Mechanics, 2019. 13(1): p. 482-492.

47. Mosavi, A. and A.R. Varkonyi-Koczy, Integration of machine learning and optimization for robot learning, R. Jablonski and R. Szewczyk, Editors. 2017, Springer Verlag. p. 349-355.

48. Nosratabadi, S., et al., Sustainable business models: A review. Sustainability (Switzerland), 2019. 11(6).

49. Qasem, S.N., et al., Estimating daily dew point temperature using machine learning algorithms. Water (Switzerland), 2019. 11(3).

50. Rezakazemi, M., A. Mosavi, and S. Shirazian, ANFIS pattern for molecular membranes separation optimization. Journal of Molecular Liquids, 2019. 274: p. 470476.

51. Riahi-Madvar, H., et al., Comparative analysis of soft computing techniques RBF, $M L P$, and ANFIS with MLR and MNLR for predicting grade-control scour hole geometry. Engineering Applications of Computational Fluid Mechanics, 2019. 13(1): p. 529-550.

52. Shabani, S.; Samadianfard, S.; Taghi Sattari, M.; Shamshirband, S.; Mosavi, A.; Kmet, T.; R. Várkonyi-Kóczy, A. Modeling Daily Pan Evaporation in Humid Cli-mates Using Gaussian Process Regression. Preprints 2019, 2019070351 (doi: 10.20944/preprints201907.0351.v1).

53. Shamshirband, S.; Hadipoor, M.; Baghban, A.; Mosavi, A.; Bukor J.; Annamaria R. Varkonyi-Koczy, Developing an ANFIS-PSO Model to predict mercury emissions in Combustion Flue Gases. Preprints 2019, 2019070165 (doi: 10.20944/preprints201907.0165.v1). 
54. Shamshirband, S., et al., Ensemble models with uncertainty analysis for multi-day ahead forecasting of chlorophyll a concentration in coastal waters. Engineering Applications of Computational Fluid Mechanics, 2019. 13(1): p. 91-101.

55. Shamshirband, S., A. Mosavi, and T. Rabczuk, Particle swarm optimization model to predict scour depth around bridge pier. arXiv preprint arXiv:1906.08863, 2019.

56. Taherei Ghazvinei, P., et al., Sugarcane growth prediction based on meteorological parameters using extreme learning machine and artificial neural network. Engineering Applications of Computational Fluid Mechanics, 2018. 12(1): p. 738-749.

57. Torabi, M., et al., A Hybrid clustering and classification technique for forecasting short-term energy consumption. Environmental Progress and Sustainable Energy, 2019. 38(1): p. 66-76.

58. Torabi, M., et al., A Hybrid Machine Learning Approach for Daily Prediction of Solar Radiation, in Lecture Notes in Networks and Systems. 2019, Springer. p. 266-274.

59. Reynel-Ávila, H.E., A. Bonilla-Petriciolet, and J.C. Tapia-Picazo, An artificial neural network-based NRTL model for simulating liquid-liquid equilibria of systems present in biofuels production. Fluid Phase Equilibria, 2019. 483: p. 153-164.

60. Camberos, S.A., et al., Neuronal modeling of a two stages anaerobic digestion process for biofuels production. IFAC-PapersOnLine, 2018. 51(13): p. 408-413.

61. Sewsynker-Sukai, Y., F. Faloye, and E.B.G. Kana, Artificial neural networks: an efficient tool for modelling and optimization of biofuel production (a mini review). Biotechnology \& Biotechnological Equipment, 2017. 31(2): p. 221-235.

62. Mancini, M., V.M. Taavitsainen, and G. Toscano, Comparison of three different classification methods performance for the determination of biofuel quality by means of NIR spectroscopy. Journal of Chemometrics, 2019.

63. Feng, X., et al., Rapid and non-destructive measurement of biofuel pellet quality indices based on two-dimensional near infrared spectroscopic imaging. Fuel, 2018. 228: p. 197-205. 
64. Faizollahzadeh Ardabili, S., B. Najafi, and S. Shamshirband, Fuzzy logic method for the prediction of cetane number using carbon number, double bounds, iodic, and saponification values of biodiesel fuels. Environmental Progress \& Sustainable Energy, 2019.

65. Wong, K.I., et al., Sparse Bayesian extreme learning machine and its application to biofuel engine performance prediction. Neurocomputing, 2015. 149(Part A): p. 397404.

66. Faizollahzadeh Ardabili, S., et al., Using SVM-RSM and ELM-RSM Approaches for Optimizing the Production Process of Methyl and Ethyl Esters. Energies, 2018. 11(11): p. 2889.

67. Erdoğan, S., et al., The best fuel selection with hybrid multiple-criteria decision making approaches in a CI engine fueled with their blends and pure biodiesels produced from different sources. Renewable Energy, 2019: p. 653-668.

68. Deo, R.C., et al., Adaptive Neuro-Fuzzy Inference System integrated with solar zenith angle for forecasting sub-tropical Photosynthetically Active Radiation. Food and Energy Security, 2019. 8(1).

69. Ardabili, S., Mosavi, A., Mahmoudi, Mesri Gundoshmian, T, Nosratabadi, S., Varkonyi-Koczy, A., Modelling temperature variation of mushroom growing hall us-ing artificial neural networks, Preprints 2019.

70. Mesri Gundoshmian, T., Ardabili, S., Mosavi, A., Varkonyi-Koczy, A., Prediction of combine harvester performance using hybrid machine learning modeling and re-sponse surface methodology, Preprints 2019.

71. Ardabili, S., Mosavi, A., Varkonyi-Koczy, A., Systematic review of deep learning and machine learning models in biofuels research, Preprints 2019.

72. Ardabili, S., Mosavi, A., Varkonyi-Koczy, A., Advances in machine learning modeling reviewing hybrid and ensemble methods, Preprints 2019. 
73. Ardabili, S., Mosavi, A., Varkonyi-Koczy, A., Building Energy information: demand and consumption prediction with Machine Learning models for sustainable and smart cities, Preprints 2019.

74. Faizollahzadeh ardabili, S.; Mosavi, A.; Dehghani, M.; R. Várkonyi-Kóczy, A. Deep Learning and Machine Learning in Hydrological Processes, Climate Change and Earth Systems: A Systematic Review. Preprints 2019, 2019080166 (doi: 10.20944/preprints201908.0166.v1).

75. Mohammadzadeh S., D.; Karballaeezadeh, N.; Mohemmi, M.; Mosavi, A.; R. Várkonyi-Kóczy, A. Urban Train Soil-Structure Interaction Modeling and Analysis. Preprints 2019, 2019080162 (doi: 10.20944/preprints201908.0162.v1).

76. Mosavi, A.; Faizollahzadeh ardabili, S.; R. Várkonyi-Kóczy, A. List of Deep Learning Models. Preprints 2019, 2019080152 (doi: 10.20944/preprints201908.0152.v1).

77. Nosratabadi, S.; Mosavi, A.; Keivani, R.; Faizollahzadeh ardabili, S.; Aram, F. State of the Art Survey of Deep Learning and Machine Learning Models for Smart Cities and Urban Sustainability. Preprints 2019, 2019080154 (doi: 10.20944/preprints201908.0154.v1).

78. Perez, H.; Tah, J.H.M.; Mosavi, A. Deep Learning for Detecting Building Defects Using Convolutional Neural Networks. Sensors 2019, 19, 3556. 